\title{
Posterior auricular pain caused by the trigger points in the sternocleidomastoid muscle aggravated by psychological factors
}

\section{-A case report-}

\author{
Sam Hong Min, Seong-Ho Chang, Se Keun Jeon, Seung Zhoo Yoon, Ji-Yong Park, and Hye Won Shin \\ Department of Anesthesiology and Pain Medicine, Anam Hospital, Korea University College of Medicine, Seoul, Korea
}

Psychological factors play a significant role in the pain mechanism, and psychological approaches may be useful complements to traditional medical and surgical treatments in pain management. The authors report a case of recurrent severe posterior auricular pain caused by trigger points in the right sternocleidomastoid muscle and influenced by stressful psychological situations (e.g., family affairs, job loss) in a 50-year-old man. (Korean J Anesthesiol 2010; 59: S229-S232)

Key Words: Myofascial pain syndrome, Posterior auricular pain, Psycological factor, Sternocleidomastoid muscle, Trigger point injection.

Pain physicians must evaluate carefully the origin of the sustained pain against the appropriate treatment, and should not overlook factors that may contribute to unsatisfactory treatment results in spite of appropriate and sufficient treatment. Knowing a patient's psychological state and living conditions is important for an optimal outcome, and significant evidence exists regarding the relationship between pain and psychosocial factors, especially in chronic pain cases [1-4]. Although mentioned in several articles [5,6], the acknowledgement of an association between psychological factors and myofascial pain syndrome (MPS) is not wellestablished.

In the present case study, the patient whose myofascial pain was responsive but not completely treated by the needling technique was finally treated after psychological interview and supportive therapy. The results imply that psychological factors can influence myofascial pain aggravation, and may be evidence that psychological problems are aggravating factors of MPS.

\section{Case Report}

A 50-year-old male patient visited our pain clinic and complained of right posterior auricular pain, which began 4 days prior. The patient started driving a taxi 2 months ago, and his pain was initiated by rotating his head to the right side

Received: March 22, 2010. Revised: 1st, April 2, 2010; 2nd, April 10, 2010. Accepted: April 26, 2010.

Corresponding author: Seong-Ho Chang, M.D., Department of Anesthesiology and Pain Medicine, Anam Hospital, Korea University College of Medicine, 126-1, Anam-dong 5-ga, Seongbuk-gu, Seoul 136-705, Korea. Tel: 82-2-920-5771, Fax: 82-2-929-2936, E-mail: torchid@korea.ac.kr (c) This is an open-access article distributed under the terms of the Creative Commons Attribution Non-Commercial License (http:// creativecommons.org/licenses/by-nc/3.0/), which permits unrestricted non-commercial use, distribution, and reproduction in any medium, provided the original work is properly cited. 
to give the taxi fare change to a passenger. The patient felt a sudden severe right posterior auricular pain. The first visual analog scale (VAS, 0 to 10 ) was 5 but aggravated to 8 . The pain occurred unpredictably several times per hour with the duration of a few seconds each time without any triggering factor. His psychological state was very unstable and hostile, but the patient did not experience sleep disturbance from the pain. Examination by an otologist and a dentist revealed no abnormal findings. The patient had no medical history of infection, trauma, or drug use, although 1 year ago was admitted to the neurology department because of a similar pain, diagnosed with glossopharyngeal neuralgia, and was transferred to a pain clinic for a glossopharyngeal nerve block. At that time, his imaging study, including C-spine radiography and neck and brain MRI, did not reveal any pathologic findings, and because the patient was a truck driver, his symptoms improved after he quit his job and resolved a family problem.

Upon physical examination, there was a limited range of motion of approximately $20 \%$ when rotating his head to the right. The patient's pain was reproduced by pressing and squeezing several points in his right sternocleidomastoid (SCM) muscle (Fig. 1), thus, a trigger point injection (TPI) was performed with $0.25 \%$ lidocaine [7], and a $3.8 \mathrm{~cm}, 25 \mathrm{G}$ needle (KOVAX-NEEDLE $^{\circledR}$, Korea Vaccine Co., Ltd., Seoul, Korea). After injection, the VAS was lowered from 2 to 3 but returned to 8 after 2 hours. TPI was retried, and the pain was relieved. However, the patient complained again of pain via telephone a few hours later and doubted our treatment and the possibility of a full recovery. The authors explained to the patient the possibility of decreasing pain through repeated TPI. Afterwards, TPI was performed twice per week with $0.125 \%$ bupivacaine; however,

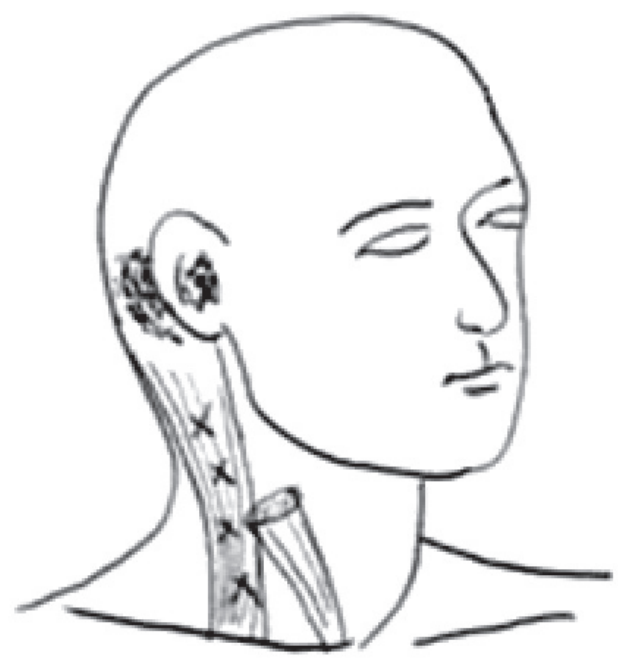

Fig. 1. Figure showing trigger points of SCM (X: trigger point, Dot: region of referred pain). the pain recurred within 2 hours after injection. Medication comprising 1,300 $\mathrm{mg}$ acetaminophen and $5 \mathrm{mg}$ diazepam 3 times per day was not effective.

Because TPI caused temporary pain relief, the authors decided to continue TPI treatment, and hypothesized that a few psychological factors may possibly be affecting the persistence and recurrence of the severe pain. After further interview, the authors determined that the patient had gotten into a very stressful psychological family situation (e.g., family affair) approximately 2 months before the initiation of the pain. One year ago, the same symptom occurred when he was frustrated by family problems and job loss, and the pain disappeared after resolution of the problems. The authors suggested that psychological factors had been contributing to trigger, prolong, and intensify the patient's pain; therefore, an attempt was made to help the patient understand the relationship between his pain and his psychological problems. Despite the author's recommended psychological supportive therapy, the patient's rejection of therapy was strong, stating that his pain was real and that he was not an insane person. Finally, the patient agreed after he was reminded of the first episode 1 year ago, which was influenced by psychological factors.

In addition, an accessory nerve block, superficial cervical nerve plexus block, and transcutaneous electric nerve stimulation (TENS) were included in the treatment plan. However, the effect of these therapies did not continue for more than 2 to 3 hours before receiving psychological therapy. On the third day after psychological therapy, the VAS was lowered to 5, and the pain frequency was reduced to 3 times per hour, with a duration of 0.5 seconds per incidence. As time progressed, pain relief increased to the patient's satisfaction. Forty days after the onset of pain, the VAS score was lowered to 2 , and the pain frequency was once per day, with a duration of 0.5 seconds per incidence. The TPI and nerve block were continued, because the pain did not completely subside. One week later, the patient's pain completely disappeared and did not recur.

\section{Discussion}

Obtaining a thorough patient history and physical examination is important in diagnosing posterior auricular pain for a number of reasons. Except for otologic problems, neuropathic conditions in the occipital, trigeminal, and glossopharyngeal nerves, arthropathy in the temporomandibular and upper zygoappophyseal joints [8], C2 radiculopathy [9], and muscleoriginated pain, including muscle trigger points, can induce peri- or posterior auricular pain, which has similar but different symptoms and signs.

In the present case, the patient described the pain character as 'piercing' and 'electric shock-like,' which can be indicative of 
trigeminal neuralgia or glossopharyngeal neuralgia. However, there was no triggering stimulus, such as conversation, chewing, head-washing, teeth brushing, and exposure to cold air or swallowing, which are common in those diseases. Glossopharyngeal neuralgia is a rare condition characterized by short and severe pain around the pharyngeal muscle and submandibular gland and usually occurs in people over 50 years of age [10]. If glossopharyngeal neuralgia is suspected, then local compression by tumors which require surgery must be excluded [11]. In the present study, the first episode of pain ended with a change in the patient's lifestyle and condition. In the second episode of pain, the patient had no trauma or infection history. However, the obvious presence of a typical palpable tender spot, patient's pain recognition of the tender spot and following limited range of motion helped the authors decide to manage the patient's pain with TPI, regardless of the previous pain episode.

MPS is a very common disease but, in unusual sites, is easily misdiagnosed as other conditions. Travell and Simons [12] described the myofascial trigger point as a hyperirritable spot, usually within a taut band of skeletal muscle, which is painful on compression and causes referred pain, motor dysfunction, and autonomic phenomena. Excessive muscle use, inadequate posture, nutritional disease, metabolic disorder, or emotional distress can cause MPS. Trigger points may be relieved by noninvasive measures, such as spray, stretch, TENS, physical therapy, and massage or invasive treatment, TPI with or without local anesthetics, corticosteroids, or botulinum toxin [13,14].

Psychological factors play a significant role in the experience, maintenance, and exacerbation of chronic and acute pain. The pain physician must consider the contributions of psychological aspects to the effectiveness of pain management [2]. There are no therapeutics guaranteed to treat chronic pain, and perfect remission is rare. Psychological therapeutic approaches may be useful complements to chronic pain management [2], although a patient's psychological state is usually considered only after pain treatment fails. Pain due to emotional distress can be exacerbated by many factors, including fear, inadequate or maladaptive support systems, inadequate personal and material coping resources, treatment-induced (iatrogenic) complications, overuse of potent drugs, inability to work, financial difficulties, prolonged litigation, disruption of usual activities, and sleep disturbance.

Although psychological factors can influence pain, physicians should not conclude that pain unresponsive to treatment is psychogenic without sufficient evaluation and treatment. Careful consultation about factors that cause, aggravate, and maintain pain which exists deep inside a patient's mind, is essential. Recommendation of psychological intervention to patients who suffer from severe sustained pain should be proposed cautiously because patients may think, 'The doctor will probably stop my treatment' or 'The doctor may think of my symptoms as malingering or mental illness'. The patient in the present case study expressed a strong denial to the proposal of psychological interview. A patient may be frustrated and have a negative response; thus, sufficient explanation to counter any negative response must be given first. In particular, in patients whose trigger point is activated from a latent state by psychological worries, MPS occasionally is misdiagnosed as a psychosomatic disorder [15].

Although why the pain recurred 2 hours after TPI and other treatments was not understood, other causes of limited effect were suspected, rather than incomplete removal of the trigger point or other pathologies, because of the patient's definite twitch responses at TPI.

The first and second pain episodes were associated with the patient's job and stressful family situation, respectively. Therefore, an inadequate driving habit was thought to have led to the onset of MPS, and the stressful psychological situations aggravated, maintained, and amplify the patient's pain. Emotional instability and anticipatory anxiety due to the sudden onset of pain led to the patient's restricted outdoor activity and allowed for him to focus on post-auricular pain. The authors hypothesized that the patient did not have an opportunity to vent, which made the pain worse and unresponsive to treatment. Pain relief with additional psychological therapy supported this hypothesis.

In summary, consideration of psychological factors is important in management of MPS that is unresponsive to conventional treatment.

\section{References}

1. Kuch K. Psychological factors and the development of chronic pain. Clin J Pain 2001; 17: S33-8.

2. Eccleston C. Role of psychology in pain management. Br J Anaesth 2001; 87: 144-52.

3. Turk DC. The role of psychological factors in chronic pain. Acta Anaesthesiol Scand 1999; 43: 885-8.

4. CME Institute of Physicians Postgraduate Press, Inc, Greist JH, Greden JF, Jefferson JW, Grivedi MH. Depression and pain. J Clin Psychiatry 2008; 69: 1970-8.

5. Hopwood MB, Abram SE. Factors associated with failure of trigger point injections. Clin J Pain 1994; 10: 227-34.

6. Esenyel M, Caglar N, Aldemir T. Treatment of myofascial pain. Am J Phys Med Rehabil 2000; 79: 48-52.

7. Iwama H, Akama Y. The superiority of water-diluted $0.25 \%$ to neat $1 \%$ lidocaine for trigger-point injections in myofascial pain syndrome: a prospective, randomized, double-blinded trial. Anesth Analg 2000; 91: 408-9.

8. Dwyer A, Aprill C, Bogduk N. Cervical zygapophyseal joint pain patterns. I: A study in normal volunteers. Spine (Phila Pa 1976) 
1990; $15: 453-7$.

9. Boes CJ. C2 myelitis presenting with neuralgiform occipital pain. Neurology 2005; 64: 1093-4.

10. Evans RW, Torelli P, Manzoni GC. Glossopharyngeal neuralgia. Headache 2006; 46: 1200-2.

11. Pearce JM. Glossopharyngeal neuralgia. Eur Neurol 2006; 55: 49-52.

12. Travell JG, Simons DG. Myofascial pain and dysfunction: the trigger point mannual. Baltimore, Williams and Wilkins. 1983, pp 1-7.
13. Sola AE, Bonica JJ. Myofascial pain syndromes. In: Myofascial pain syndromes. 3rd ed. Edited by Loeser JD, Butler SH, Chapman RC, Turk DC: Philadelphia, Lippincott Williams \& Wilkins. 2001, pp 530-42.

14. Lavelle ED, Lavelle W, Smith HS. Myofascial trigger points. Anesthesiol Clin 2007; 25: 841-51.

15. Lee WH. Myofascial Pain Syndrome. In: Pain Medicine. 3rd ed Edited by Yoon DM: Seoul, Koonja Press. 2007, pp 357-68. 